\title{
PENGARUH MEDIA FLASHCARD (KARTU BERGAMBAR) TERHADAP KEMAMPUAN KOMUNIKASI ANAK BERKEBUTUHAN KHUSUS (AUTIS) DI SDLB NEGERI KABUPATEN TANAH BUMBU TAHUN 2021
}

\author{
Liqma Amir ${ }^{1}$, Herdy Juniawan² \& Tika Sari Dewy ${ }^{3}$ \\ 1, 2, 3 Program Studi S1 Keperawatan Sekolah Tinggi Ilmu Kesehatan Darul Azhar Batulicin \\ Email : liqmaamir0708@gmail.com
}

\begin{abstract}
ABSTRAK
Latar belakang : anak autis memiliki gangguan komunikasi yang menyebabkan anak autis tidak mampu berinteraksi dengan lingkungan sekitarnya. Flashcard (kartu bergambar) diketahui dapat meningkatkan kemampuan komunikasi anak autis. Tujuan : tujuan penelitian ini untuk menganalisis pengaruh media flashcard (kartu bergambar) terhadap kemampuan komunikasi anak autis. Metode : metode Penelitian menggunakan Pre-Eksperimental dengan rancangan one group Pretest dan Posttest without control. Jumlah sampel dalam penelitian ini 12 anak autis. Hasil : hasil penelitian menggunakan Uji PairedTTest, didapatkan nilai peningkatan rata-rata dengan nilai P-Value $0,000<0,05$. Kesimpulan : kesimpulan dari penelitian ini adalah terdapat pengaruh media flashcard (kartu bergambar) terhadap kemampuan komunikasi anak autis. Disarankan bagi peneliti selanjutnya media flashcard (kartu bergambar) ini dapat dijadikan sebagai salah satu alternative untuk media promosi kesehatan pada anak berkebutuhan khusus autis
\end{abstract}

Kata Kunci: Komunikasi Anak Autis, Flashcard (kartu bergambar), Komunikasi

\begin{abstract}
Background : Autistic children have communication disorders that cause autistic children are not able to interact with the surrounding environment. Flashcards are known to improve the communication skills of autistic chidren. Purpose : The aim of this study is to analyze the influence of flashcard media (picture cards) on the ability communication for autistic children. Method : The study method was preexperimental with one group pretest and posttest without control designs. The number of samples in this study were 12 autistic children.Result : The results of the study by using the Paired T-Test, the average increase value obtained with a P-Value of $0.000<0.05$. Conclusion: The conclusion of this study, that there was an influence of flashcard media (picture cards) on the communication skills of autistic children. It was recommended for further researchers that this flashcard media (picture card) can be used as an alternative for health promotion media for children with special needs autism.
\end{abstract}

Key Words : Autistic child communication, Flashcard (Picture Cards), Communication, 


\section{Latar Belakang}

Penelitian ini penting untuk menunjang kreativitas dan kelancaran dalam berkomunikasi dan berbahasa untuk anak berkebutuhan khusus (Autis), dan dapat dijadikan salah satu kompetensi dalam bidang keperawatan sebagai penatalaksanaan keperawatan untuk tumbuh dan kembang anak. Anak autis memiliki gangguan pada interaksi social, komunikasi (baik verbal maupun non verbal), dan pola perilaku. Penyandang autism disebut juga anak autistik, autism merupakan gangguan perkembangan yang ditandai dengan adanya abnormalitas dan kelainan yang muncul sebelum anak berusia tiga tahun, dengan ciri-ciri terganggunya perkembangan, sehingga anak tidak mampu membentuk hubungan social dan komunikasi dengan baik atau secara normal, dan tidak memiliki kontak mata dengan orang lain (Saihu, 2019).

Kemampuan dalam berkomunikasi merupakan bagian terpenting dalam kehidupan sehari-hari. Dengan memiliki kemampuan berkomunikasi dan berbahasa dengan baik, anak dapat memahami dan menyampaikan informasi, meminta sesuatu yang ia sukai, menyampaikan dan mengekspresikan keinginan untuk memenuhi kebutuhan nya (Nursita, 2020). Berdasarkan penelitian Desriyani (2019) pada tahun 2011 diketahui bahwa 15,3\% populasi dunia (sekitar 978 juta orang dari 6,4 milyar estimasi jumlah penduduk tahun 2004) mengalami disabilitas sedang dan 2,9\% atau sekitar 185 juta mengalami disabilitas parah. Amerika serikat salah satu negara dengan jumlah penderita autis terbanyak.

Berdasarkan data dari Kemenkes RI tahun 2015 penderita autis di Indonesia 1:1000 lebih banyak dibandingkan tahun sebelumnya, dan Berdasarkan data dari SLBN Tanah Bumbu didapatkan bahwa 90 orang anak berkebutuhan khusus yang bersekolah di SLB dengan jenis kelamin laki-laki 66 orang siswa, dan perempuan 24 orang siswi. dengan kategori autis 12 orang siswa.

Menurut penelitian (Dinar \& Matulessy, 2015) selain komunikasi dan berbicara terdapat peningkatan pada kemampuan dalam kepatuhan dan kontak mata pada saat diberikan flashcard (kartu bergambar), ini membuktikan bahwa anak autis memerlukan terapi flashcard agar mampu menerima instruksi dan patuh, bahkan dengan instruksi yang ditekankan pada kontak mata.

Penelitian ini bertujuan untuk menganalisis pengaruh media flashcard (kartu bergambar) terhadap kemampuan komunikasi anak autis.

\section{Metode}

Lokasi penelitian ini adalah di Sekolah Dasar Luar Biasa Tanah Bumbu. Berdasarkan studi pendahuluan yang dilakukan di SLBN tahan bumbu menggunakan metode wawancara dengan salah satu guru di SLBN tanah bumbu, anak-anak yang mengalami gangguan komunikasi adalah anak berkebutuhan khusus (Autis). Waktu pelaksanaaan penelitian ini dilaksanakan pada bulan Mei 2021. Penelitian ini menggunakan Pre-Eksperimental dengan rancangan one group pre test and post test 
without control.

Penelitian ini menggunakan total sampling dengan jumlah sampel 12 anak. Instrumen yang digunakan pada pengumpulan dan pengolahan data penelitian ini adalah lembar observasi dan media flashcard (kartu bergambar). Hasil penelitian diuji dengan prametrik tes Paired T-test dengan taraf signifikansi $<0.05$.

\section{Hasil}

Dari hasil penelitian dapat dijelaskan tentang distribusi frekuensi berdasarkan kelompok usia Pada Anak Berkebutuhan Khusus ditampilkan pada Tabel 1.

Tabel 1. Distribusi Frekuensi Responden Berdasarkan Kelompok Usia Pada Anak Berkebutuhan Khusus (Autis) Di SLBN

Batulicin Kabupaten Tanah Bumbu

\begin{tabular}{cccc}
\hline No & Usia & Frekuensi (Orang) & Presentase \% \\
\hline 1 & 8 & 2 & $16.67 \%$ \\
2 & 9 & 3 & $25.00 \%$ \\
3 & 10 & 4 & $33.33 \%$ \\
4 & 11 & 2 & $16.67 \%$ \\
5 & 12 & 1 & $8.33 \%$ \\
\hline \multicolumn{2}{c}{ Total } & $\mathbf{1 2}$ & $\mathbf{1 0 0 \%}$ \\
\hline
\end{tabular}

Berdasarkan Tabel 1 diketahui hampir setengahnya responden dalam penelitian ini berusia 10 tahun $(33,33 \%)$ berjumlah 4 anak, dan sebagian kecil anak berusia 12 tahun (8,33\%). berjumlah 1 anak. Semua responden dalam penelitian ini berjenis kelamin laki-laki.

Dari hasil penelitian dapat dijelaskan tentang distribusi frekuensi berdasarkan Klasifikasi Pada Anak Autis ditampilkan pada Tabel 2.
Tabel 2. Distribusi Frekuensi Responden Berdasarkan Klasifikasi Pada Anak Autis Di SLBN Batulicin Kabupaten Tanah Bumbu

\begin{tabular}{cccc}
\hline No & Klasifikasi & $\begin{array}{c}\text { Frekuensi } \\
\text { (orang) }\end{array}$ & Presentase (\%) \\
\hline 1. & Ringan & 10 & $83.33 \%$ \\
\hline 2. & Sedang & 2 & $16.67 \%$ \\
\hline 3. & Berat & 0 & 0 \\
\hline & Total & $\mathbf{1 2}$ & $\mathbf{1 0 0 \%}$ \\
\hline & Berdasarkan & Tabel diatas diketahui
\end{tabular}

bahwa dalam penelitian ini hampir seluruhnya $(83.33 \%)$ berjumlah 10 orang anak mengalami autis ringan, dan sebagian kecil (16.67\%) berjumlah 2 orang anak mengalami autis sedang.

Dari hasil penelitian dapat dijelaskan tentang Kemampuan Komunikasi Anak Autis Sebelum Dan Sesudah Diberikan Media Flashcard Hari Ke 1 ditampilkan pada Tabel 3.

Tabel 3. Kemampuan Komunikasi Anak Autis Sebelum Dan Sesudah Diberikan Media Flashcard (Kartu Bergambar) hari ke-1

\begin{tabular}{|c|c|c|c|c|c|c|}
\hline \multirow{2}{*}{$\begin{array}{c}\mathbf{N} \\
\mathbf{0}\end{array}$} & \multirow{2}{*}{$\begin{array}{c}\text { Klasifikasi } \\
\text { kemampuan } \\
\text { komunikasi }\end{array}$} & \multicolumn{2}{|c|}{ Pretest 1} & \multicolumn{2}{|c|}{$\begin{array}{c}\text { Posttest } \\
1\end{array}$} & \multirow[t]{2}{*}{ P value } \\
\hline & & f & $\%$ & $\mathbf{f}$ & $\%$ & \\
\hline 1. & Kurang & 7 & $\begin{array}{c}58 . \\
3\end{array}$ & 7 & 58.3 & \multirow{4}{*}{0,002} \\
\hline 2. & Cukup & 5 & $\begin{array}{c}41 . \\
7\end{array}$ & 5 & 41.7 & \\
\hline 3. & Baik & 0 & 0 & 0 & 0 & \\
\hline 4. & Sangat baik & 0 & 0 & 0 & 0 & \\
\hline & Total & 12 & 100 & 12 & 100 & \\
\hline
\end{tabular}

Dari hasil penelitian dapat dijelaskan tentang Kemampuan komunikasi anak autis dengan menggunakan media flash Card ditampilkan pada Gambar 1. 


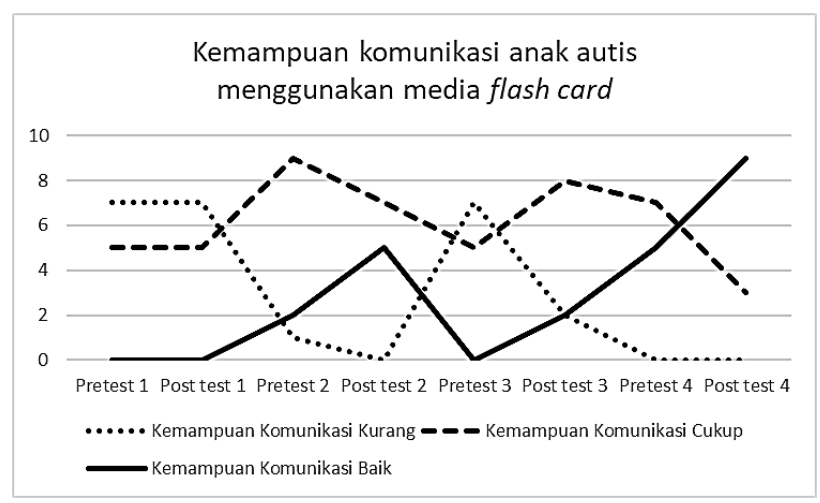

Gambar 1. Kemampuan komunikasi anak autis dengan menggunakan media flas Card

Berdasarkan tabel grafik garis diatas diketahui bahwa sebelum diberikan Media Flashcard (Kartu Bergambar) terhadap kemampuan komunikasi anak berkebutuhan khusus (autis) terlihat perkembangan kemampuan anak dalam berkomunikasi menggunakan flash card.

Pada pretest 1, sebagian besar responden mengalami kemampuan komunikasi kurang, demikian juga hasil post testnya. Pada hari ke-2 post test terjasi peningkatan, sebagian besar reponden mengalami kemampuan komunikasi cukup, sedangkan di hari ke-3 posttest sebagian besar $(58 \%)$ responden mengalami kemampuan komunikasi cukup, dan di hari ke-4 posttest didapatkan bahwa sebagian besar (75\%)responden mengalami kemampuan komunikasi baik.

Dari hasil penelitian dapat dijelaskan tentang Kemampuan Komunikasi Anak Autis Sebelum Dan Sesudah Diberikan Media Flashcard Hari ke 2 ditampilkan pada Tabel 4.
Tabel 4. Kemampuan Komunikasi Anak Autis Sebelum Dan Sesudah Diberikan Media Flashcard (Kartu Bergambar) hari ke-2

\begin{tabular}{|c|c|c|c|c|c|c|}
\hline \multirow{2}{*}{ No } & \multirow{2}{*}{$\begin{array}{l}\text { Klasifikasi } \\
\text { kemampuan } \\
\text { komunikasi }\end{array}$} & \multicolumn{2}{|c|}{ Pretest 3} & \multicolumn{2}{|c|}{ Posttest 3} & \multirow{2}{*}{$\begin{array}{c}P \\
\text { value }\end{array}$} \\
\hline & & f & $\%$ & f & $\%$ & \\
\hline 1. & Kurang & 1 & 8.3 & 0 & 0 & \multirow{4}{*}{0,025} \\
\hline 2. & Cukup & 9 & 75.0 & 7 & 58.3 & \\
\hline 3. & Baik & 2 & 16.7 & 5 & 41.7 & \\
\hline \multirow[t]{2}{*}{4.} & Sangat baik & 0 & 0 & 0 & 0 & \\
\hline & Total & 12 & 100 & 12 & $100 \%$ & \\
\hline
\end{tabular}

pada kelompok intervensi yang artinya $\mathrm{H} 1$ ditolak dan $\mathrm{H} 0$ diterima sehingga dapat disimpulkan bahwa tidak ada perbedaan antara sebelum dan sesudah diberikan media flashcard (kartu bergambar) terhadap kemampuan komunikasi anak berkebutuhan khusus (autis).

Dari hasil penelitian dapat dijelaskan tentang Analisis Perbedaan Sebelum Dan Sesudah Diberikan Media Flashcard (Kartu Bergambar) terhadap kemampuan komunikasi anak berkebutuhan khusus (autis) ditampilkan pada Tabel 5.

Tabel 5. Analisis Perbedaan Sebelum Dan Sesudah Diberikan Media Flashcard (Kartu Bergambar) terhadap kemampuan komunikasi anak berkebutuhan khusus (autis) Pada Hari $\mathrm{Ke}-2$

\begin{tabular}{ccccccc}
\hline \multirow{2}{*}{$\begin{array}{c}\text { N } \\
\text { o }\end{array}$} & $\begin{array}{c}\text { Klasifikasi } \\
\text { kemampuan } \\
\text { komunikasi }\end{array}$ & \multicolumn{2}{c}{ Pretest 2 } & \multicolumn{2}{c}{ Posttest 2 } & $\begin{array}{c}\boldsymbol{P} \\
\text { value }\end{array}$ \\
\cline { 3 - 7 } f & \% & f & \% & \\
\hline 1. & Kurang & 7 & 58.3 & 2 & 16.7 & \\
3. & Cukup & 5 & 41.7 & 8 & 66.7 & \\
4. & Baik & 0 & 0 & 2 & 16.7 & 0,001 \\
\hline & Sangat baik & 0 & 0 & 0 & 0 & \\
\hline
\end{tabular}


Berdasarkan hasil P value pada hari ke 2, $\mathrm{P}=0,001 \quad(<0,05)$ pada kelompok intervensi yang artinya $\mathrm{H} 1$ diterima dan $\mathrm{H} 0$ ditolak sehingga dapat disimpulkan bahwa ada perbedaan antara sebelum dan sesudah diberikan media flashcard (kartu bergambar) terhadap kemampuan komunikasi anak autis pada hari ke2.

Dari hasil penelitian dapat dijelaskan tentang Analisis Perbedaan Sebelum Dan Sesudah Diberikan Media Flashcard (Kartu Bergambar) terhadap kemampuan komunikasi anak berkebutuhan khusus (autis) Pada Hari Ke3 ditampilkan pada Tabel 6.

Tabel 6. Analisis Perbedaan Sebelum Dan

Sesudah Diberikan Media Flashcard (Kartu

Bergambar) terhadap kemampuan komunikasi anak berkebutuhan khusus

\begin{tabular}{ccccccc}
\hline & $\begin{array}{c}\text { Klasifikasi } \\
\text { Nemampuan }\end{array}$ & \multicolumn{2}{c}{ Pretest 3 } & \multicolumn{2}{c}{ Posttest 3 } & $\begin{array}{c}\text { P } \\
\text { value }\end{array}$ \\
\cline { 3 - 7 } komunikasi & f & \% & f & \% & \\
\hline 1. & Kurang & 1 & 8.3 & 0 & 0 & \\
2. & Cukup & 9 & 75.0 & 7 & 58.3 & 0,025 \\
3. & Baik & 2 & 16.7 & 5 & 41.7 & \\
4. & Sangat baik & 0 & 0 & 0 & 0 & \\
\hline & Total & $\mathbf{1 2}$ & $\mathbf{1 0 0}$ & $\mathbf{1 2}$ & $\mathbf{1 0 0}$ & \\
\hline
\end{tabular}

Berdasarkan hasil p value pada Tabel 6 didapatkan $\mathrm{P}=0,025 \quad(<0,05)$ pada kelompok intervensi yang artinya $\mathrm{H} 1$ diterima dan $\mathrm{H} 0$ ditolak sehingga dapat disimpulkan bahwa ada perbedaan antara sebelum dan sesudah diberikan media flashcard (kartu bergambar) terhadap kemampuan komunikasi anak autis pada hari ke3.
Tabel 7. Analisis Perbedaan Sebelum Dan Sesudah Diberikan Media Flashcard (Kartu Bergambar) terhadap kemampuan komunikasi anak berkebutuhan khusus (autis) Pada Hari $\mathrm{Ke}-4$

\begin{tabular}{ccccccc}
\hline \multirow{2}{*}{ No } & $\begin{array}{c}\text { Klasifikasi } \\
\text { kemampuan } \\
\text { komunikasi }\end{array}$ & \multicolumn{2}{c}{ Pretest $\mathbf{4}$} & \multicolumn{2}{c}{ Posttest $\mathbf{4}$} & $\begin{array}{c}\text { P } \\
\text { value }\end{array}$ \\
\cline { 3 - 7 } 1. & Kurang & 0 & 0 & 0 & 0 & \\
2. & Cukup & 7 & 58.3 & 3 & 25.0 & \\
3. & Baik & 5 & 41.7 & 9 & 75.0 & 0,004 \\
4. & Sangat baik & 0 & 0 & 0 & 0 & \\
\hline & Total & $\mathbf{1 2}$ & $\mathbf{1 0 0}$ & $\mathbf{1 2}$ & $\mathbf{1 0 0}$ & \\
\hline & & & &
\end{tabular}

Berdasarkan hasil p value pada hari ke-4, $\mathrm{P}=0,004(<0,05)$ pada kelompok intervensi yang artinya $\mathrm{H} 1$ diterima dan $\mathrm{H} 0$ ditolak sehingga dapat disimpulkan bahwa ada perbedaan antara sebelum dan sesudah diberikan media flashcard (kartu bergambar) terhadap kemampuan komunikasi anak autis pada hari ke-4.

Berdasarkan Tabel diatas diketahui bahwa sesudah diberikan media flashcard (kartu bergambar) anak autis pada kelompok intervensi diperoleh hasil bahwa hari ke-1 anak belum sepenuhnya berinteraksi dengan lingkungan nya, Kemudian pada posttest di hari ke-2, 3 \& ke-4 terdapat perbedaan sesudah pemberian media flashcard (kartu bergambar).

Dapat disimpulkan bahwa ada pengaruh media flashcard (kartu bergambar) terhadap kemampuan komunikasi anak berkebutuhan khusus (autis). Responden sudah mulai mampu mengikuti arahan yang diberikan oleh peneliti, mampu menyebutkan kosakata dengan benar dan responden mulai mampu mengucapkan bahasa yang jelas, dan mampu beinteraksi dengan baik. 
Dari hasil penelitian dapat dijelaskan tentang Analisis Pengaruh Media Flashcard (Kartu Bergambar) Terhadap Kemampuan Komunikasi Pada Anak Berkebebutuhan khusus (Autis) ditampilkan pada Tabel 8.

Tabel 8. Analisis Pengaruh Media Flashcard

(Kartu Bergambar) Terhadap Kemampuan Komunikasi Pada Anak Berkebebutuhan khusus (Autis)

\begin{tabular}{|c|c|c|c|c|}
\hline $\begin{array}{l}\text { Kemampuan } \\
\text { Komunikasi }\end{array}$ & $\mathbf{N}$ & $\begin{array}{l}\text { Pretest } \\
\text { Dan } \\
\text { Posttest }\end{array}$ & $\begin{array}{l}\text { Mean } \\
\text { Rank }\end{array}$ & $\begin{array}{c}\text { P- } \\
\text { Value }\end{array}$ \\
\hline \multirow{8}{*}{$\begin{array}{c}\text { Kemampuan } \\
\text { komunikasi } \\
\text { anak autis }\end{array}$} & 12 & Pretest1 & 37.00 & \multirow{8}{*}{$\begin{array}{c}0,000< \\
0,005\end{array}$} \\
\hline & 12 & Pretest2 & 39.33 & \\
\hline & 12 & Pretest3 & 49.58 & \\
\hline & 12 & Pretest 4 & 58.00 & \\
\hline & 12 & $\begin{array}{c}\text { Posttest } \\
1\end{array}$ & 38.00 & \\
\hline & 12 & $\begin{array}{c}\text { Posttest } \\
2 \\
\end{array}$ & 44.83 & \\
\hline & 12 & $\begin{array}{c}\text { Posttest } \\
3 \\
\end{array}$ & 53.00 & \\
\hline & 12 & $\begin{array}{c}\text { Posttest } \\
4\end{array}$ & 61.58 & \\
\hline
\end{tabular}

Total 106

Berdasarkan Tabel 8 dengan uji paired $T$ test didapatkan $P$-Value $=0,000(<0,005)$ yang artinya $\mathrm{H} 1$ diterima dan $\mathrm{H} 0$ ditolak sehingga dapat disimpulkan bahwa ada pengaruh media flashcard (kartu bergambar) dari hari ke-1,2,3 dan 4 terhadap kemampuan komunikasi anak autis.

\section{Pembahasan}

Berdasarkan tabel diatas diperoleh bahwa tingkat kemampuan komunikasi anak berkebutuhan khusus (Autis) sebelum diberikan media flashcard (kartu bergambar) Sebagian besar (58.3\%) 7 anak memiliki tingkat kemampuan komunikasi dalam kategori kurang dan sesudah diberikan media flashcard (kartu bergambar) sebagian besar (75\%) 9 anak memiliki tingkat kemampuan komunikasi dalam kategori baik.

Sebelum diberikan media flashcard (kartu bergambar) kemampuan komunikasi anak kurang, dikarenakan Anak autis memiliki ciri yang khas, lebih suka menyendiri, bermain sendiri dan tidak mau berinteraksi dengan lingkungan di sekitarnya. Sehingga perbendaharaan kata nya terbatas yang menyebabkan anak tidak mampu berkomunikasi dengan bahasa yang baik.

Menurut penelitian yang dilakukan oleh Nursita (2020) anak autis cenderung menghabiskan waktu sendiri dan tidak mau berkomunikasi dan berinteaksi dengan lingkungannya. Berdasarkan hasil penelitian Pramesi (2021) kemampuan komunikasi anak autis kurang yang disebabkan anak tidak pernah diajak berinteraksi dan bersosialisasi dengan lingkungan luar sehingga anak tidak menyerap beberapa kosakata dari sosialisasi tersebut, salah satu faktor yang menyebabkan terjadinya autis adalah faktor genetik yang menjadi penyebab utama autis karena dapat mengubah perkembangan otak, terutama fungsi hubungan sel saraf. Terjadinya perubahan sel saraf pusat akan menyebabkan otak kanan untuk mengingat tidak berfungsi dengan baik, sehingga anak tidak mampu mengingat kosakata yang pernah dipelajarinya.

Sesudah diberikan nya media flashcard (kartu bergambar) anak dapat membuat kalimat sederhana dengan flashcard (kartu bergambar, 
selain itu anak juga mulai belajar mengeja kosa kata, emosi mulai terkendali, lebih mengingat gambar dan keterangan yang ada di flashcard (kartu bergambar) dan mulai mengikuti arahan dari peneliti.

Sejalan dengan penelitian Dinar \& Matulessy (2015) selain komunikasi dan berbicara terdapat peningkatan pada kemampuan dalam kepatuhan dan kontak mata pada saat diberikan flashcard (kartu bergambar), ini membuktikan bahwa anak autis memerlukan terapi flashcard agar mampu menerima instruksi dan patuh, bahkan dengan instruksi yang ditekankan pada kontak mata. Media flashcard (kartu bergambar) dengan warna mencolok sehingga anak tertarik untuk bermain, dan mengikuti arahan.

Penelitian ini dilakukan selama 14 hari dengan 4 kali pertemuan, pada pertemuan pertama anak masih kurang dalam dalam berkomunikasi dikarenakan pusat perhatian anak yang masih kurang, kontak mata yang tidak bertahan lama, dan lebih asyik dengan dunia nya sendiri, pada pertemuan yang ke 2 setelah diberikan pretest dan postest anak mulai mampu menyebutkan kosakata dengan pelafalan yang jelas.

Sejalan dengan penelitian yang pernah dilakukan Aulia (2019) dalam Mahendra (2020) sebelum diberikan media flashcard anak belum mampu menyebutkan kosa kata benda disekitarnya dan kemampuan bahasa ekspresif masih kurang, dan sesudah diberikan media flashcard mampu meningkatkan perbendaharaan kata pada anak autis, anak mampu menyesuaikan kosa kata yang dipilih untuk berbicara dengan orang sekitarnya. Media flashcard mempermudah anak autis karena gambar yang disertakan pada kartu mencolok dan menarik perhatian anak.

Berdasarkan hasil penelitian menunjukan ada pengaruh media flashcard (kartu bergambar) terhadap kemampuan komunikasi pada anak berkebutuhan khusus (Autis) hal ini diperkuat dengan hasil uji statistic dengan menggunakan uji Paired T-Test didapatkan nilai $P$ Value sig. $(2$ tailed $)=0,000(<0,05)$ yang artinya $\mathrm{H} 0$ ditolak dan H1 diterima sehingga bermakna ada pengaruh media flashcard (kartu bergambar) terhadap kemampuan komunikasi anak berkebutuhan khusus (Autis).

Sejalan dengan penelitian ( $\mathrm{T} \&$ Matulessy, 2015) menunjukkan bahwa terdapat peningkatan pada kemampuan dalam kepatuhan dan kontak mata pada saat sebelum dan sesudah diberikan media flashcard hal ini membuktikan bahwa anak autis memerlukan terapi flashcard agar mampu menerima instruksi dan patuh, bahkan dengan instruksi yang ditekankan pada kontak mata. Hal ini sejalan dengan pendapat dari Handoyo (2018) bahwa anak autis memiliki gejala kesulitan menggunakan indra mata, yaitu memahami kontak mata dengan orang lain, termasuk pula kontak mata dengan terapis dan tema sebaya. Terapi flashcard telah banyak diterapkan untuk mengurangi ketidakmampuan anak dalam mematuhi instruksi, terkhusus yang berkaitan dengan kemampuan kontak mata. 


\section{Kesimpulan}

Kesimpulan dari penelitian ini adalah terdapat pengaruh media flashcard (kartu bergambar) terhadap kemampuan komunikasi anak autis. Disarankan bagi peneliti selanjutnya media flashcard (kartu bergambar) ini dapat dijadikan sebagai salah satu alternative untuk media promosi kesehatan pada anak berkebutuhan khusus autis.

\section{Ucapan Terimakasih}

Ucapan terimakasih disampaikan kepada kepala sekolah SDLB Batulicin yang telah memberikan izin penelitian sehingga berjalan dengan lancar dan terimakasih kepada guru-gur SDLB Batulicin yang mendukung peneliti selama berjalan nya penelitian ini.

\section{Daftar Pustaka}

Desriyani, Y., I. \& F. (2019). Burden of Parents in Children with Disability at Sekolah Luar Biasa Negeri Cileunyi. NurseLine Journal, 4(1).

https://doi.org/https://doi.org/10.19184/nlj. v4i1.8696

Dinar, R. T. \& Matulessy, A. (2015). Pengaruh Terapi Bermain Flashcard untuk Meningkatkan Interaksi Sosial pada Anak Autis di Miracle Centre Surabaya. Jurnal Psikologi Indonesia, 4(01), 51-60.

Handoyo. (2018). Terapi Bermain Flashcard untuk Perkembangan Bahasa pada Anak Autis.

Mahendra. (2020). Pengaruh Penggunaan Media ABACA Flashcard terhadap Kemampuan Membaca Permulaan Anak Autis di Sekolah Khusus Cita Hati Bunda Sidoarjo.

Nursita, D., L. \& N. (2020). Media Flash Card untuk Meningkatkan Kemampuan Komunikasi Ekspresif pada Anak dengan Autisme di Pendidikan Anak USia Dini. Jurnal Keislaman Dan Pendidikan, 1(2), $18-26$.

Pramesi. (2021). Penggunaan Media Flashcard Terhadap Kemampuan Berbicara Anak Autis. Jurnal Pendidikan Tambusai, 4(1).

Saihu, M. (2019). Komunikasi Pendidikan terhadap Anak Berkebutuhan Khusu di Sekolah Khusus Asy-Syifa Larangan. Jurnal Pendidikan Islam Dan Manajemen Pendidikan Islam, 1(3), 418-440. https://doi.org/http://dx.doi.org/10.36671/a ndragogi.v1i3.66

T, D. R., \& Matulessy, A. (2015). Pengaruh Terapi Bermain FlashcardUntuk Meningkatkan Interaksi Sosial Pada Anak Autis di Miracle Centre Surabaya. Persona:Jurnal Psikologi Indonesia, 4(1). https://doi.org/10.30996/persona.v4i1.490 